\title{
Missed opportunities: racial and neighborhood socioeconomic disparities in emergency colorectal cancer diagnosis and surgery
}

\author{
Sandi L Pruitt ${ }^{1,2^{*}}$, Nicholas O Davidson ${ }^{3,4}$, Samir Gupta ${ }^{5,6}$, Yan Yan ${ }^{4,7}$ and Mario Schootman ${ }^{8}$
}

\begin{abstract}
Background: Disparities by race and neighborhood socioeconomic status exist for many colorectal cancer (CRC) outcomes, including screening use and mortality. We used population-based data to determine if disparities also exist for emergency CRC diagnosis and surgery.

Methods: We examined two emergency CRC outcomes using 1992-2005 population-based U.S. SEER-Medicare data. Among CRC patients aged $\geq 66$ years, we examined racial (African American vs. white) and neighborhood poverty disparities in two emergency outcomes defined as: 1) newly diagnosed CRC or 2) CRC surgery associated with: obstruction, perforation, or emergency inpatient admission. Multilevel logistic regression (patients nested in census tracts) analyses adjusted for sociodemographic, tumor, and clinical covariates.

Results: Of 83,330 CRC patients, 29.1\% were diagnosed emergently. Of 55,046 undergoing surgery, 26.0\% had emergency surgery. For both outcomes, race and neighborhood poverty disparities were evident. A significant race by poverty interaction $(p<.001)$ was noted: poverty rate was associated with both outcomes among African Americans, but not whites. Compared to whites in low poverty $(<10 \%)$ neighborhoods, African Americans in high poverty ( $\geq 20 \%)$ neighborhoods had increased odds of emergency diagnosis (AOR: 1.50, 95\% Cl: 1.38-1.63) and surgery (AOR: $1.63,95 \% \mathrm{Cl}: 1.47-1.81$ ).

Conclusions: Emergency CRC outcomes are associated with high poverty residence among African Americans in this population-based study, potentially contributing to observed disparities in CRC morbidity and mortality. Targeted efforts to increase CRC screening among African Americans living in high poverty neighborhoods could reduce preventable disparities.
\end{abstract}

Keywords: Colorectal cancer, Emergency outcomes, Disparities, Race, Socioeconomic status, SEER-Medicare

\section{Background}

Colorectal cancer (CRC) screening results in dramatically improved survival $[1,2]$ and can prevent late-stage disease and associated serious and emergent complications including obstruction, perforation, hemorrhage, and peritonitis. These complications, when presenting acutely, are considered emergencies-posing immediate risks to life or long-term impairment-and require immediate intervention including surgical management and intensive care unit stays. Of those diagnosed emergently and

\footnotetext{
*Correspondence: Sandi.Pruitt@utsouthwestern.edu

'Department of Clinical Sciences, University of Texas Southwestern Medical Center, 5323 Harry Hines Blvd E1, 410D Dallas, TX, USA

${ }^{2}$ Harold C. Simmons Comprehensive Cancer Center, Dallas, TX, USA

Full list of author information is available at the end of the article
}

receiving curative resection, both short- and long-term outcomes, including mortality and medical and surgical complications, are significantly worse than those receiving elective curative resection [3-5]. For example, a U.S. National Inpatient Sample study demonstrated that emergency resection was associated with a 3-fold increase of in-hospital mortality, longer hospital stays, and greater hospital costs [6]. Emergency resection is also associated with suboptimal long-term outcomes. A U.S. Surveillance Epidemiology and End Results (SEER)-Medicare study of 30,685 stage I-III colon cancer patients found that nonelective resection was associated with significantly worse five-year disease-specific survival (Hazard Ratio: 1.30,

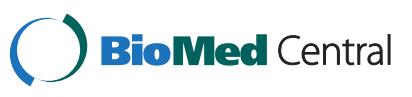

(c) 2014 Pruitt et al.; licensee BioMed Central. This is an Open Access article distributed under the terms of the Creative Commons Attribution License (http://creativecommons.org/licenses/by/2.0), which permits unrestricted use, distribution, and reproduction in any medium, provided the original work is properly credited. The Creative Commons Public Domain Dedication waiver (http://creativecommons.org/publicdomain/zero/1.0/) applies to the data made available in this article, unless otherwise stated. 
$\mathrm{p}<.001$ ), even after adjustment for pre-, peri-, and postoperative covariates [7].

CRC emergencies may disproportionately affect African Americans and low socioeconomic status (SES) populations. For example, in a U.S. population-based study of 127,975 CRC patients undergoing resection in 2002, African Americans were more likely to have emergency resection [6]. However, in the same study, median income of patients' zip code was not associated with emergency resection [6]. Studies from England and Canada, however, demonstrate that CRC patients living in low SES neighborhoods are more likely to be diagnosed emergently $[4,8,9]$. African American and disadvantaged, low-SES populations are less likely to have obtained and maintained cancer screening than their counterparts and partly as a result, experience a disproportionate cancer burden across numerous CRC outcomes [10-12]. For example, compared to whites, African American men and women have a $22-23 \%$ higher CRC incidence rate and a $46-53 \%$ higher CRC mortality rate, respectively [13]. In a study comparing those living in counties where $<10 \%$ population lived in poverty, both African Americans (OR: 1.13; 95\% CI: 1.03-1.25) and whites (OR: 1.10; 95\% CI: 1.06-1.15) living in counties with $\geq 20 \%$ poverty had higher odds of distant stage CRC [14].

The overwhelming majority of studies on emergency diagnosis or surgery of CRC originate from Europe or Canada, include small samples, and are not populationbased. Thus, the U.S. experience, particularly race and SES disparities, has not been adequately studied. Further, while there is documented geographic variation in CRC outcomes such as screening and mortality, [15-20] the extent of neighborhood variation in CRC emergencies is unknown. Neighborhood variation indicates that shared neighborhood-level characteristics, in addition to individual characteristics, are associated with emergencies, which could suggest a role for geographically-targeted prevention strategies.

To our knowledge, there is only one population-based U.S. study on emergency CRC diagnosis, [21] and none that concurrently examine both emergency diagnosis and surgery. Many patients diagnosed emergently have advanced disease, multimorbidity, low functional status, or poor prognosis, which could postpone or preclude curative resection, particularly African Americans and those of low SES who often present with more advanced disease [14]. Thus, there is a paucity of information about the distribution and correlates of emergency diagnosis (with or without emergency curative resection) in the U.S.

Here we describe 1) variation across neighborhoods and 2) race and neighborhood SES disparities in two outcomes, emergency CRC diagnosis and surgery, among U.S. CRC patients aged $\geq 66$ years. Given lower rates of screening and worse CRC morbidity and mortality among African
Americans $[6,10,12,13]$ and patients in low SES neighborhoods $[4,8,9,14]$, we hypothesized these populations would have higher rates of both emergency outcomes.

\section{Methods \\ Data sources}

Data were obtained from an existing linkage of the 1992-2005 National Cancer Institute's (NCI) SEER program data with 1991-2006 Medicare claims files from the Centers for Medicare and Medicaid. Data access was granted by the NCI. As detailed elsewhere, [22] linked SEER-Medicare data provide a rich source of information on Medicare patients included in SEER, a nationally representative collection of population-based cancer registries. Ninety-four percent of cancer patients reported to SEER aged 65 years or older have been successfully linked with Medicare data [22]. Data for this study were available from 12 registries representing approximately $14 \%$ of the U.S. population, [23] including states (Connecticut, Hawaii, Iowa, New Mexico, and Utah), metropolitan areas (Atlanta, Detroit, Los Angeles, San Francisco-Oakland, San JoseMonterey, and Seattle), and rural Georgia. This study was reviewed by the Institutional Review Board at Washington University and determined to be exempt from IRB oversight.

\section{Study population}

The study population included male and female patients aged $\geq 66$ with a diagnosis of a first primary invasive colorectal cancer occurring from 1992 through 2005. We included only those aged $\geq 66$ to allow for one-year of complete claims data pre-diagnosis to determine comorbidity. All patients had full coverage by both Medicare Parts A and B from one year pre-diagnosis until 120 days past primary surgery or until initiation of adjuvant chemotherapy, whichever came first. We excluded patients with appendix cancer, only autopsy or death certificate records, and members of HMOs. We excluded patients with a diagnosis of Crohn's disease, ulcerative colitis, inflammatory bowel disease, or diverticulitis (ICD-9 556.X, 555.X, $562.01,562.03,562.11,562.13)$ in the year prior to diagnosis. Finally, we also excluded patients $(n=5,529)$ missing year 2000 census tract in the SEER-Medicare data.

For the emergency surgery analysis, we included only patients with CRC surgeries (identified using ICD9 procedure codes described below) and excluded patients with abdominal or pelvic postoperative adhesions (ICD-9 $560.81,568.0,614.6)$ in the pre-surgery year due to a high likelihood of emergency surgery for these conditions. We further excluded patients with neoadjuvant chemotherapy or radiation occurring in the year until 7 days before surgery as an emergency in this situation could merely reflect complications of a preexisting cancer [24]. 


\section{Study variables}

\section{Emergency diagnosis and surgery}

We defined emergency diagnosis and surgery as yes/no variables by the presence of any of 3 emergency Medicare claims indicators based on ICD9 codes and an inpatient admission type indicator, including: 1) obstruction (560.89, 560.9 ); 2) perforation (569.83); or 3) emergency inpatient admission (admtype $=1$; patient required immediate medical intervention as a result of severe, life threatening, or potentially disabling conditions). These indicators were identified from previous literature [6,7,9,24-26] and were selected because they are highly correlated with CRC emergencies; emergency surgeries are commonly a result of obstruction and/or perforation [7]. Further, chosen indicators are unlikely to identify nonemergent symptoms or unrelated conditions (e.g. rectal bleeding is relatively nonspecific and could indicate minor bleeding or hemorrhoids). For inclusion as an emergency outcome, we specified that dates associated with the emergency indicators fall within 1) SEER month and year of initial CRC diagnosis (because day of diagnosis is not available in SEER) (emergency diagnosis); or 2) within \pm 3 days of the first of any CRC surgery (e.g. resections, pelvic exenteration, colostomy, [not including colostomy reversals]) (emergency surgery).

\section{Race and socioeconomic (SES) status}

We compared non-Hispanic African Americans to nonHispanic whites. We defined SES as the percent of population living in poverty in the patient's residential census tract at time of CRC diagnosis. We selected this indicator because census tract-level poverty rate is a robust indicator of SES, is associated with a variety of health outcomes in diverse populations and across time, and has relevance for policymakers $[27,28]$. We used 2000 U.S. Census data using the following commonly used categories: $<9.9 \%$, $10-19.9 \%$, and $\geq 20 \%[29,30]$.

\section{Covariates}

Multiple covariates associated with emergency CRC outcomes in earlier studies $[6,7,9,21]$ were examined. Covariates obtained from SEER data included: year of diagnosis, age (66-69, 70-74, 75-79, 80-84, $\geq 85$ ), sex, SEER historic stage (localized, regional, distant), tumor location (right [cecum: 18.0, ascending colon: 18.2, hepatic flexure of colon: 18.3, and transverse colon: 18.4] vs. left [splenic flexure of colon: 18.5, descending colon: 18.6, sigmoid colon: 18.7, rectosigmoid: 19.9, rectum: 20.9]), histology (mucinous adenocarcinoma/signet ring cell, other adenocarcinoma, other, unknown), and tumor grade (low [well/ moderately differentiated] or high [poorly differentiated/ undifferentiated/anaplastic] or unknown).

Covariates obtained from Medicare claims included: prior hospitalizations, comorbidity, preventable hospitalizations, number of endoscopies, and Medicaid and Medicare ("dual eligibility"). Prior hospitalizations occurring between 12-1 months prior to diagnosis were measured as yes/no. To measure comorbidity, we searched inpatient or carrier claims for multiple chronic conditions (e.g. myocardial infarction, diabetes, dementia, or AIDS) occurring between 12-1 months pre-diagnosis using Charlson comorbidity index-Klabunde adaptation [31,32]. We further classified comorbidity as none, one, or two or more following common practice. Preventable hospitalizations identify poor ambulatory health care outcomes and can represent a breakdown in access to or processes of primary care. Following methods described elsewhere, [33] we searched one-year pre-diagnosis of inpatient claims for potentially preventable hospitalizations, including asthma, diabetes, hypertension, pneumonia, and compared those with one or more preventable hospitalizations to those with none. Because claims provide accurate information on endoscopy procedures but are less reliable for stool blood testing and cannot distinguish screening from diagnostic tests, [34] we measured total number of endoscopies (colonoscopies and sigmoidoscopies) in the pre-diagnosis year, but were not able to control for complete CRC screening history starting at age 50. Dual-eligibility was defined as Medicaid eligibility for at least 1 month during the pre-diagnosis year. Census-tract urban/rural status (metropolitan, micropolitan, or rural) was measured using 2000 Census Rural Urban Continuum Area codes [35].

\section{Statistical analysis}

We describe sample characteristics and frequency of emergency diagnosis and emergency surgery using descriptive and chi-square statistics. We examine associations of race and neighborhood poverty rate, including a race by poverty interaction term, with both outcomes. We present 6 models: 1) empty model; 2) unadjusted race model; 3) unadjusted poverty model; 4) unadjusted race and poverty model; 5) adjusted race and poverty main effects model; and 6) adjusted race and poverty interaction model. Empty models include no predictor variables, but include a hierarchical structure, and are fit for the purpose of quantifying variation (random effects) at the census tract level. We multiplied race and poverty rate variables to determine if an interaction was present on a synergistic scale and retained the main effects of race and poverty in the model. Covariates were retained if they were associated with outcomes in bivariate analyses $(\mathrm{p}<.05)$. All models were fit using multilevel logistic regression to account for nesting of patients within residential census tracts, using SAS PROC GLIMMIX (SAS Institute Inc, Cary, NC).

To facilitate interpretation of census-tract ("neighborhood") level random effects, we present variance and standard error and Median Odds Ratio (MOR). The MOR quantifies unexplained cluster heterogeneity [36,37] on a scale directly comparable to odds ratios associated with 
other model variables [38]. MOR is based on the random effects variance component $(\mathrm{V})$ from the regression model: $M O R=\exp (0.95 \sqrt{V})$. It is interpreted as the median value of the ratio of predicted odds of the outcome for two patients with equivalent covariates randomly chosen from two different neighborhoods. MOR is always $\geq 1 ; 1.0$ indicates no variation between neighborhoods and larger values indicate greater geographic variation.

In a sensitivity analysis, we disaggregated each emergency outcome into 2 component variables (emergencies defined as obstruction and/or perforation [because only $1.1 \%$ and $1.2 \%$ of all diagnoses and surgeries, respectively, were associated with perforations] and emergency admission type $[$ admtype $=1]$ ) and re-fit all multilevel logistic regression models separately for each outcome.

\section{Results}

Of all 83,330 eligible patients, $29.1 \%$ had an emergency diagnosis. Of all patients undergoing surgery $(n=55,046)$, $26.0 \%$ had an emergency surgery. Table 1 presents sample characteristics by presence of emergency diagnosis and surgery status. All but one of the sample characteristics differed $(\mathrm{p}<.001)$ by emergency status and were included in the adjusted models. Occurrence of emergency diagnosis and emergency surgery did not significantly change over time $(\mathrm{p}>.05)$; therefore year of diagnosis was not included in the adjusted models. Of patients diagnosed emergently and undergoing surgery, $84.0 \%$ had emergency surgery. Of patients undergoing emergency surgery, nearly all (94.0\%) were also classified as having an emergency diagnosis (data not shown).

\section{Emergency diagnosis}

Table 2 presents results from unadjusted and adjusted multilevel analyses. Patients in the diagnosis sample ( $\mathrm{n}=83,330)$ were nested within 14,191 census tracts (range: 1-87 patients per tract). In all unadjusted and adjusted main effects models, emergency diagnosis was more likely for African Americans compared to whites, and those living in the highest poverty census tracts, compared to those in the lowest poverty census tracts. In the adjusted main effects model (Model 5), African Americans (vs. whites) (OR 1.28 [95\% CI: 1.20-1.37]) and those living in census tracts with the highest poverty rates $(\geq 20 \%$ vs. <10\%) (OR 1.11 [95\% CI: 1.04-1.18]) were more likely to have emergency diagnosis.

\section{Emergency surgery}

Patients in the surgery sample $(n=55,046)$ were nested within 12,886 census tracts (range: 1-66 patients per tract). In all unadjusted and adjusted main effects models, African Americans, compared to whites, and those living in the highest poverty census tracts, compared to those in the lowest poverty tracts, were more likely to have emergency surgery. In the adjusted main effects model (Model 5), African Americans (vs. whites OR: 1.33 [95\% CI: 1.231.44]) and those living in the highest poverty census tracts ( $\geq 20 \%$ vs. $<10 \%$ poverty: OR: 1.11 [95\% CI: $1.04-1.19]$ ) were more likely to have emergency surgery.

\section{Race by neighborhood poverty interactions for emergency diagnosis and surgery}

Race by neighborhood poverty interactions $(\mathrm{p}<.001)$ were evident for both outcomes in the final adjusted interaction models (Model 6). Table 3 presents the number of patients and the percent with both outcomes by group as well as the adjusted race and poverty interaction effects. In the interaction models, neighborhood poverty was no longer associated with either outcome among whites. African Americans living in the lowest poverty neighborhoods were equally likely to have emergency outcomes as whites living in similar conditions. Compared to whites in the lowest poverty neighborhoods $(<10 \%)$, African Americans living in neighborhoods with $\geq 10 \%$ poverty rate demonstrated higher odds of both outcomes. African Americans living in the highest poverty neighborhoods $(\geq 20 \%)$ had the greatest odds of both emergency diagnosis (AOR: 1.50, 95\% CI: 1.38-1.63) and surgery (AOR: $1.63,95 \%$ CI: 1.47-1.81).

\section{Neighborhood variation}

Statistically significant variability in emergency diagnosis was present across census tracts for both outcomes in all models (Tables 2 and 3). In empty models (including no predictor variables), the MOR for census-tract variability in emergency diagnosis was 1.87 . This can be interpreted as follows: if a patient switched from living in a randomly selected tract with low emergency diagnosis rate to randomly selected tract with a higher emergency diagnosis rate, her odds of emergency diagnosis would be 1.87 times higher (in the median). Neighborhood variability in emergency surgery $(\mathrm{MOR}=1.97)$ was of similar magnitude. Neighborhood variability persisted, with similar magnitude, in multivariable models, suggesting that none of the covariates, including census tract poverty rate, accounted for census-tract variability in either outcome.

In sensitivity analyses, we examined, separately, two different indicators of both emergency diagnosis and surgery (data not shown). For both outcomes, in all models, African Americans and those living in higher poverty neighborhoods had higher odds of both 1) obstruction and/or perforations; and 2) emergency admissions $(\mathrm{p}<.001$ for all comparisons).

\section{Discussion}

To our knowledge this is the first U.S. population-based study to demonstrate neighborhood variation and race and SES disparities in both emergency CRC diagnosis and 
Table 1 Sample characteristics of colorectal cancer patients, by emergency diagnosis and emergency surgery status

\begin{tabular}{|c|c|c|c|c|c|c|c|c|c|c|}
\hline \multirow{3}{*}{ Characteristic } & \multicolumn{5}{|c|}{ Diagnosis $(n=83,330)^{a}$} & \multicolumn{5}{|c|}{ Surgery $(n=55,046)^{a}$} \\
\hline & \multicolumn{2}{|c|}{$\begin{array}{l}\text { No emergency } \\
\text { diagnosis }(n=59,082)\end{array}$} & \multicolumn{2}{|c|}{$\begin{array}{l}\text { Emergency } \\
\text { diagnosis }(n=24,248)\end{array}$} & \multirow[t]{2}{*}{$\mathrm{p}\left(\mathrm{Chi}^{2}\right)$} & \multicolumn{2}{|c|}{$\begin{array}{l}\text { No emergency } \\
\text { surgery }(n=40,740)\end{array}$} & \multicolumn{2}{|c|}{$\begin{array}{l}\text { Emergency } \\
\text { surgery }(n=14,306)\end{array}$} & \multirow[t]{2}{*}{$\mathrm{p}\left(\mathrm{Chi}^{2}\right)$} \\
\hline & $\mathrm{n}$ & $\%$ & $\mathbf{n}$ & $\%$ & & $\mathrm{n}$ & $\%$ & $\mathbf{n}$ & $\%$ & \\
\hline \multicolumn{11}{|l|}{ Race } \\
\hline White & 54527 & 71.90 & 21313 & 28.10 & $<.0001$ & 37957 & 75.01 & 12643 & 24.99 & $<.0001$ \\
\hline African American & 4555 & 60.81 & 2935 & 39.19 & & 2783 & 62.60 & 1663 & 37.40 & \\
\hline \multicolumn{11}{|c|}{ Neighborhood poverty rate } \\
\hline$<10 \%$ & 35999 & 71.72 & 14198 & 28.28 & $<.0001$ & 25254 & 74.81 & 8505 & 25.19 & $<.0001$ \\
\hline 10-19.9\% & 14902 & 71.98 & 5801 & 28.02 & & 10170 & 75.09 & 3374 & 24.91 & \\
\hline$\geq 20 \%$ & 8181 & 65.82 & 4249 & 34.18 & & 5316 & 68.66 & 2427 & 31.34 & \\
\hline \multicolumn{11}{|l|}{ Sex } \\
\hline Male & 27154 & 73.36 & 9860 & 26.64 & $<.0001$ & 18215 & 75.71 & 5843 & 24.29 & $<.0001$ \\
\hline Female & 31928 & 68.94 & 14388 & 31.06 & & 22525 & 72.69 & 8463 & 27.31 & \\
\hline Age (mean [SD]) & 77.2 & 7.1 & 79.6 & 7.6 & $<.0001$ & 76.8 & 6.8 & 78.9 & 7.4 & $<.0001$ \\
\hline \multicolumn{11}{|l|}{ Year } \\
\hline 1992-1996 & 24621 & 70.68 & 10214 & 29.32 & 0.4126 & 9311 & 74.05 & 3263 & 25.95 & 0.9327 \\
\hline 1997-2001 & 13092 & 71.21 & 5292 & 28.79 & & 14847 & 74.08 & 5195 & 25.92 & \\
\hline 2002-2005 & 21369 & 70.97 & 8742 & 29.03 & & 16582 & 73.93 & 5848 & 26.07 & \\
\hline \multicolumn{11}{|l|}{ Medicaid enrollee } \\
\hline No & 52170 & 72.54 & 19753 & 27.46 & $<.0001$ & 36395 & 75.51 & 11802 & 24.49 & $<.0001$ \\
\hline Yes & 6912 & 60.59 & 4495 & 39.41 & & 4345 & 63.44 & 2504 & 36.56 & \\
\hline \multicolumn{11}{|c|}{ Rural urban commuting area } \\
\hline Metropolitan & 46093 & 69.38 & 20346 & 30.62 & $<.0001$ & 31657 & 72.45 & 12037 & 27.55 & $<.0001$ \\
\hline Micropolitan & 5246 & 76.23 & 1636 & 23.77 & & 3595 & 78.91 & 961 & 21.09 & \\
\hline Rural & 7743 & 77.36 & 2266 & 22.64 & & 5488 & 80.75 & 1308 & 19.25 & \\
\hline \multicolumn{11}{|l|}{ Stage } \\
\hline Local & 25470 & 78.60 & 6936 & 21.40 & $<.0001$ & 17622 & 79.48 & 4549 & 20.52 & $<.0001$ \\
\hline Regional & 20160 & 69.12 & 9006 & 30.88 & & 16936 & 72.69 & 6363 & 27.31 & \\
\hline Distant & 9840 & 60.94 & 6307 & 39.06 & & 5436 & 64.66 & 2971 & 35.34 & \\
\hline \multicolumn{11}{|l|}{ Tumor location } \\
\hline Left & 31557 & 73.93 & 11127 & 26.07 & $<.0001$ & 20204 & 75.47 & 6568 & 24.53 & $<.0001$ \\
\hline Right & 25162 & 68.09 & 11790 & 31.91 & & 19953 & 73.04 & 7366 & 26.96 & \\
\hline \multicolumn{11}{|l|}{ Tumor Grade } \\
\hline Low & 40222 & 72.40 & 15337 & 27.60 & $<.0001$ & 30066 & 75.09 & 9976 & 24.91 & $<.0001$ \\
\hline High & 10551 & 68.11 & 4941 & 31.89 & & 8134 & 72.08 & 3150 & 27.92 & \\
\hline \multicolumn{11}{|l|}{ Histology } \\
\hline Other adenocarcinoma & 49541 & 71.73 & 19526 & 28.27 & $<.0001$ & 35208 & 74.46 & 12078 & 25.54 & $<.0001$ \\
\hline $\begin{array}{l}\text { Mucinous } \\
\text { adenocarcinoma/signet } \\
\text { ring cell }\end{array}$ & 6252 & 68.95 & 2816 & 31.05 & & 4920 & 73.01 & 1819 & 26.99 & \\
\hline Other & 2365 & 64.09 & 1325 & 35.91 & & 544 & 61.40 & 342 & 38.60 & \\
\hline \multicolumn{11}{|l|}{ Comorbidity } \\
\hline 0 & 34535 & 73.76 & 12284 & 26.24 & $<.0001$ & 24359 & 76.19 & 7613 & 23.81 & $<.0001$ \\
\hline 1 & 14000 & 69.73 & 6077 & 30.27 & & 9889 & 73.86 & 3500 & 26.14 & \\
\hline
\end{tabular}


Table 1 Sample characteristics of colorectal cancer patients, by emergency diagnosis and emergency surgery status (Continued)

\begin{tabular}{|c|c|c|c|c|c|c|c|c|c|c|}
\hline$\geq 2$ & 9628 & 62.06 & 5887 & 37.94 & & 6492 & 67.03 & 3193 & 32.97 & \\
\hline \multicolumn{11}{|c|}{ Preventable hospitalization } \\
\hline No & 55900 & 72.62 & 21077 & 27.38 & $<.0001$ & 38522 & 75.20 & 12704 & 24.80 & $<.0001$ \\
\hline Yes & 3182 & 50.09 & 3171 & 49.91 & & 2218 & 58.06 & 1602 & 41.94 & \\
\hline Prior hospitalization & & & & & $<.0001$ & & & & & \\
\hline No & 38866 & 82.62 & 8178 & 17.38 & & 23910 & 82.93 & 4920 & 17.07 & \\
\hline Yes & 20216 & 55.71 & 16070 & 44.29 & & 16830 & 64.20 & 9386 & 35.80 & \\
\hline \multicolumn{11}{|l|}{ Endoscopies/prior year } \\
\hline None & 32028 & 67.93 & 15118 & 32.07 & $<.0001$ & 19435 & 69.11 & 8685 & 30.89 & $<.0001$ \\
\hline 1 & 16806 & 75.27 & 5521 & 24.73 & & 13345 & 80.29 & 3277 & 19.71 & \\
\hline$\geq 2$ & 10248 & 73.96 & 3609 & 26.04 & & 7960 & 77.25 & 2344 & 22.75 & \\
\hline
\end{tabular}

${ }^{\mathrm{a}}$ Numbers may not add up to total due to missing data.

surgery. Observed disparities persisted after adjustment for a diverse array of socioeconomic, clinical, and tumor covariates. Among the strengths of this study is that we utilized multilevel models to demonstrate neighborhood variation in emergency CRC diagnosis and surgery.

Observed disparities and neighborhood variation in $\mathrm{CRC}$ emergencies indicate that breakdowns are occurring across the CRC diagnosis and treatment continuum that are systematically influenced by race, poverty, and/or neighborhood. Conceptual models of the CRC diagnosis and treatment continuum provide a framework for understanding where these break-downs are occurring. For example, the CRC screening process continuum delineates transitions from risk assessment to screening, detection, diagnosis, and treatment for asymptomatic patients undergoing CRC screening [39]. Likewise, for symptomatic CRC patients, The Aarhus statement [40] reviews models $[41,42]$ that describe the events and time intervals leading from CRC symptom appraisal and detection to diagnosis and treatment. There may be multiple identifiable break-down points across these continuums contributing to suboptimal screening uptake or delayed diagnosis and/or treatment, thus leading to CRC emergencies. Future interventions designed to prevent CRC emergencies and eliminate disparities will need to explicitly acknowledge the role of race, SES, and neighborhood influences throughout the CRC continuum.

Race and SES disparities evident in our study have been observed in some but not all previous U.S. studies, and no studies to our knowledge have tested whether neighborhood poverty affects emergency outcomes in African Americans and whites equally. Previous large, multi-state U.S. studies have demonstrated that African Americans face higher risk of emergency resection [6,7]. In one of these same studies, however, zip code median income was not associated with emergency resection [6]. In another study from Michigan, African American race and lower census tract median annual household income were associated with increased odds of emergency CRC diagnosis in bivariate but not in multivariate analyses [21]. Differences in study design, populations, and case ascertainment may explain these divergent findings. For example, the Michigan study did not measure the urgency/emergency of the CRC diagnosis itself, but classified patients as to whether they had an ED visit within the month of or month before CRC diagnosis [21]. Further, other studies used zip code- or census tract- level median income, whereas we used a measure of census tract poverty rate with a priori cut-points that allow for nonlinear trends, as recommended by Krieger et al. $[27,43,44]$.

There are several possible explanations for the interactive effects of race and neighborhood poverty we observed. African American and disadvantaged, low-SES populations are less likely to have obtained and maintained cancer screening than their counterparts [10-12]. They also may delay seeking care or experience health system delays once engaged in the healthcare system. These populations are less likely to have a regular primary care physician and have reduced access to care [45-47]. However, emerging evidence suggests that insurance and access to care alone do not entirely explain observed disparities $[48,49]$. Even in a study of Medicare beneficiaries with a usual physician, rates of recent CRC screening were considerably lower among patients with low SES $[49,50]$. Other factors such as patient-physician communication, discrimination in health care, logistical challenges such as transportation, the ability to take time off of work, and capacity to navigate health system bureaucracies may also play a role. The race by poverty interaction $(\mathrm{p}<.001)$ whereby poverty rate was associated with both outcomes only among African Americans suggests that African Americans in high poverty neighborhoods face additional, substantial barriers to CRC screening and/or timely diagnosis. More research is needed to better understand the dual effects 
Table 2 The unadjusted and adjusted main effects between race and neighborhood poverty rate on emergency diagnosis and emergency surgery and neighborhood random effects

\begin{tabular}{|c|c|c|c|c|c|c|c|c|c|}
\hline \multirow[t]{2}{*}{ Characteristic } & $\begin{array}{l}\text { Model } 1 \\
\text { empty }{ }^{\mathrm{a}} \text { model }\end{array}$ & \multicolumn{2}{|c|}{$\begin{array}{l}\text { Model } 2 \text { unadjusted } \\
\text { race model }\end{array}$} & $\begin{array}{l}\text { Model } 3 \text { unadjusted } \\
\text { poverty model }\end{array}$ & \multicolumn{5}{|c|}{ 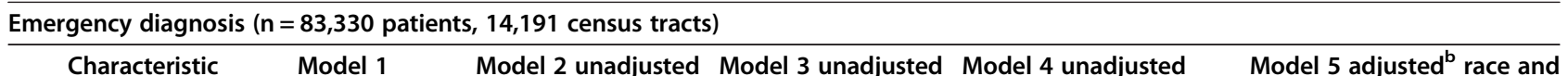 } \\
\hline & \multicolumn{9}{|c|}{ Odds ratios and $95 \%$ confidence intervals } \\
\hline \multicolumn{10}{|l|}{ Race } \\
\hline White & - & 1 & & - & & 1 & & 1 & \\
\hline African American & - & 1.58 & $1.50-1.67$ & - & & 1.48 & $1.40-1.57$ & $1.28(1.2$ & 1.37) \\
\hline \multicolumn{10}{|c|}{$\begin{array}{l}\text { Neighborhood poverty } \\
\text { rate }\end{array}$} \\
\hline$<10 \%$ & - & \multicolumn{2}{|l|}{-} & 1 & & \multicolumn{2}{|l|}{1} & \multicolumn{2}{|l|}{1} \\
\hline $10-19.9 \%$ & - & \multicolumn{2}{|l|}{-} & 1.01 & $0.97-1.05$ & 0.98 & $0.94-1.02$ & \multicolumn{2}{|c|}{$0.98(1.04-1.18)$} \\
\hline \multirow[t]{2}{*}{$\geq 20 \%$} & - & & & 1.32 & $1.26-1.39$ & 1.17 & $1.11-1.23$ & $1.11(1.0$ & 1.18) \\
\hline & \multicolumn{9}{|c|}{ Neighborhood random effects } \\
\hline Variance (se) & $.4317(.0114)$ & \multicolumn{2}{|c|}{$.4073(.0110)$} & \multicolumn{2}{|c|}{$.4225(.0112)$} & \multicolumn{2}{|c|}{$.4061(.0110)$} & \multicolumn{2}{|c|}{$.4887(.0157)$} \\
\hline Median odds ratio & 1.87 & \multicolumn{2}{|l|}{1.84} & \multicolumn{2}{|l|}{1.86} & \multicolumn{2}{|l|}{1.84} & \multicolumn{2}{|l|}{1.95} \\
\hline \multicolumn{10}{|c|}{ Emergency surgery ( $n=55,046$ patients, 12,886 census tracts) } \\
\hline \multirow[t]{2}{*}{ Characteristic } & Model $1^{\text {a }}$ & \multicolumn{2}{|c|}{ Model 2} & \multicolumn{2}{|c|}{ Model 3} & \multicolumn{2}{|c|}{ Model 4} & \multicolumn{2}{|c|}{ Model $5^{b}$} \\
\hline & \multicolumn{9}{|c|}{ Odds ratios and $95 \%$ confidence intervals } \\
\hline \multicolumn{10}{|l|}{ Race } \\
\hline White & - & 1 & & - & & 1 & & 1 & \\
\hline African American & - & 1.74 & $1.63-1.87$ & - & & 1.63 & $1.51-1.76$ & 1.33 & $1.23-1.44$ \\
\hline $\begin{array}{l}\text { Neighborhood pover } \\
\text { rate }\end{array}$ & & & & & & & & & \\
\hline$<10 \%$ & - & - & & 1 & & 1 & & 1 & \\
\hline $10-19.9 \%$ & - & - & & 1.01 & $0.96-1.06$ & 0.97 & $0.92-1.02$ & 0.98 & $0.92-1.03$ \\
\hline$\geq 20 \%$ & - & - & & 1.36 & $1.28-1.45$ & 1.17 & $1.10-1.25$ & 1.11 & $1.04-1.19$ \\
\hline & & & & & ighborhood ran & ndom effe & & & \\
\hline Variance (se) & $.5086(.0160)$ & .4843 & 0155) & .4994 & 157) & $.4826(.0$ & & $.4410(.01$ & \\
\hline Median odds ratio & 1.97 & 1.94 & & 1.96 & & 1.94 & & 1.88 & \\
\hline
\end{tabular}

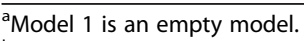

${ }^{b}$ Model 5 includes the following covariates: sex, urban/rural, Medicaid, comorbidity, prior hospitalization, preventable hospitalization, endoscopies in prior year, stage, grade, histology, and tumor location.

Values in bold represent odds ratios for which the $95 \%$ confidence interval does not include the value one.

and mechanisms of neighborhood poverty and race on CRC outcomes.

Notably, the neighborhood variability observed in our study persisted even after controlling for all covariates, including neighborhood poverty rate, indicating significant unexplained neighborhood variation in both outcomes. These results confirm a growing body of research suggesting that CRC outcomes, including screening, incidence, stage, and mortality, vary across geography $[17,19,51-53]$. For example, a prior study identified significant censustract level variation in CRC survival that remained unexplained after accounting for individual covariates and neighborhood SES [19]. A more recent study identified census tract level variation in CRC screening that persisted even after accounting for the impact of physician and clinic- level influences using cross-classified statistical models [53]. Observed geographic variations in CRC outcomes remain poorly understood but may be a result of many factors such as practice patterns, managed care spillover, endoscopic capacity, or organizational culture within and across health systems.

Our finding of race and neighborhood SES disparities provides additional evidence of the disproportionate burden of CRC morbidity and mortality borne by African Americans and low-SES populations. CRC emergencies result in both short-and long-term negative impacts on morbidity, including postoperative complications, length of hospital stay, hospital readmissions, treatment cost, 
Table 3 Interaction between race and neighborhood poverty rate on emergency diagnosis and emergency surgery and neighborhood random effects in adjusted race and poverty interaction models (Model 6) ${ }^{\mathrm{a}}$

\begin{tabular}{|c|c|c|c|c|c|c|c|c|}
\hline & \multicolumn{4}{|c|}{ Emergency diagnosis } & \multicolumn{4}{|c|}{ Emergency surgery } \\
\hline & Total & $\begin{array}{l}\text { Percent } \\
\text { emergencies }\end{array}$ & \multicolumn{2}{|c|}{$\begin{array}{l}\text { Odds ratios and } 95 \% \\
\text { confidence intervals }\end{array}$} & Total & $\begin{array}{l}\text { Percent } \\
\text { emergencies }\end{array}$ & \multicolumn{2}{|c|}{$\begin{array}{l}\text { Odds ratios and } 95 \% \\
\text { confidence intervals }\end{array}$} \\
\hline$<10 \%$ & 48767 & 28.1 & 1 & & 32922 & 25.0 & 1 & \\
\hline $10-19.9 \%$ & 18903 & 27.3 & 0.97 & $0.92-1.02$ & 12433 & 24.0 & 0.99 & 0.93-1.05 \\
\hline$\geq 20 \%$ & 8170 & 29.9 & 1.04 & $0.98-1.12$ & 5245 & 26.8 & 1.06 & $0.98-1.15$ \\
\hline \multicolumn{9}{|l|}{ Black } \\
\hline$<10 \%$ & 1430 & 33.9 & 1.09 & $0.95-1.25$ & 837 & 31.1 & 1.09 & $0.92-1.30$ \\
\hline $10-19.9 \%$ & 1800 & 35.8 & 1.16 & $1.02-1.31$ & 1111 & 34.6 & 1.27 & $1.09-1.47$ \\
\hline$\geq 20 \%$ & 4260 & 42.4 & 1.50 & $1.38-1.63$ & 2498 & 40.8 & 1.63 & $1.47-1.81$ \\
\hline Variance (se) & \multicolumn{6}{|c|}{$.4881(.0157)$} & \multicolumn{2}{|c|}{$.6254(.0221)$} \\
\hline Median odds ratio & \multicolumn{6}{|c|}{1.95} & \multicolumn{2}{|c|}{2.13} \\
\hline
\end{tabular}

${ }^{a}$ Models adjusted for the following covariates: sex, urban/rural, Medicaid, comorbidity, prior hospitalization, preventable hospitalization, endoscopies in prior year, stage, grade, histology, and tumor location, and the main effects of race and neighborhood poverty.

Values in bold represent odds ratios for which the $95 \%$ confidence interval does not include the value one.

and mortality, [6,7,54-56] and likely also influence psychosocial outcomes and quality of life. The higher number of CRC emergencies among African Americans in high poverty neighborhoods may account for some of the disproportionate burden in CRC morbidity and mortality in these populations. Future research should examine interactions between race and poverty and should explore the extent to which race and SES disparities in emergency diagnosis account for observed disparities in morbidity and mortality.

It is difficult to directly compare the rate of emergencies we observed to other studies given different sampling strategies, populations, time periods under study, and methods of ascertaining CRC emergencies. Among 4 population-based U.S. studies, numbers range considerably. A National Inpatient Sample study reported 10.6\% of CRC patients aged 65 and older had emergency resections in 2002, defined as surgery in the presence of perforation, peritonitis, or obstruction [6]. In Michigan, 23\% of CRC patients aged 66 years and older, diagnosed 1996-2000, had emergency diagnoses [21]. Using a measure of inpatient resection acuity, a SEER-Medicare study of Stage I-III colon cancer patients diagnosed 1996-2003 found that $40 \%$ of patients had urgent/emergent resections [7]. Another SEER-Medicare study of colon cancer patients with adenocarcinoma diagnosed 1991-1996, found that 19.7\% had emergent hospitalizations and 9.1\% had obstruction or perforation [26]. This last study by Schrag et al. used the same ICD9 codes as in the present study, together with the same or similar Medicare claim code for emergent hospital admission [26]. A validated and widely used measure of emergent diagnoses and surgeries would facilitate comparisons across populations and over time.
Emergency colorectal cancer resection has been identified as "the clearest evidence on an individual level for a failure of screening" [54]. Thus, CRC emergencies may be an indicator to monitor progress in cancer screening initiatives over time $[4,24,57]$. In the absence of CRC screening, CRC emergencies may be the consequence of delays occurring after symptom presentation [40]. Accordingly, monitoring CRC emergencies over time may also provide insight into factors influencing diagnostic or treatment delays, such as access to care. Notably, unlike a Canadian study that documented a $24 \%$ relative decrease (from 24-18\%) in emergency CRC surgeries between 1993-2001, [24] we found no significant change in either emergency outcome over time $(\mathrm{p}>.05)$. Given that an average of 10-15 years elapse between adenomatous polyp development and invasive cancer, [58,59] and that Medicare began covering some CRC screening modalities in 1998, adding colonoscopy for screening of average risk adults in 2001, [60] it may be too soon to detect potential downward trends in CRC emergencies. Given recent shifts in economic and health policy trends, it is unclear whether race and SES disparities in CRC emergencies will persist, diminish, or potentially increase over time.

Our results should be interpreted in light of several limitations. First, we include only Medicare-insured patients aged 66 or older and therefore cannot generalize to younger or uninsured patients. Second, although we searched claims for symptoms and codes indicating emergencies in previous studies, [6,7,9,24-26] some misclassification may have occurred. For example, we may have missed additional emergencies indicated by rectal bleeding (the severity of which cannot be measured with Medicare claims), in which case true incidence may be higher. Last, while we measured the number of lower endoscopies in the pre-diagnosis year, 
we could not measure complete CRC screening history nor endoscopic procedure quality, nor could we distinguish between screening or diagnostic procedures.

Despite these limitations, our study has several advantages over previous research. We conducted a multilevel study using a large population-based sample of U.S. CRC patients, used complete inpatient and outpatient claim data, and were able to adjust for a diverse array of tumor, patient, and neighborhood-level covariates. We further provided the first evidence of neighborhood variation and race and SES disparities in both emergency diagnosis and surgery.

\section{Conclusions}

We documented neighborhood, race and SES disparities in CRC emergencies, where African Americans living in high poverty neighborhoods have the highest odds of two emergency outcomes and where significant neighborhood variation remains unexplained. Targeted interventions to increase screening in these vulnerable populations would reduce these preventable disparities.

\section{Abbreviations \\ CRC: Colorectal cancer screening; SES: Socioeconomic status; OR: Odds ratio; AOR: Adjusted odds ratio; SEER: Surveillance epidemiology and end results program. \\ Competing interests \\ The authors declare that they have no competing interests. \\ Authors' contributions \\ SLP conceived the study and drafted the manuscript. NOD, SG, YY, and MS participated in study design, provided suggestions for statistical analysis, provided critical feedback and edited the manuscript. MS collected data. YY performed the statistical analysis. All authors read and approved the final manuscript.}

\section{Acknowledgements}

We gratefully acknowledge James Struthers for his data management and programming services. This work was supported by the National Cancer Institute (CA137750) and the National Center for Research Resources Washington University-ICTS (KL2 RR024994) and the Cancer Prevention Research Institute of Texas (CPRIT R1208). NOD was supported in part by NIH grant DK52574. This study used the linked SEER-Medicare database. The authors acknowledge the efforts of the Applied Research Program, NCl; the Office of Research, Development and Information, CMS; Information Management Services (IMS), Inc;; and the Surveillance, Epidemiology, and End Results (SEER) Program tumor registries in the creation of the SEER-Medicare database. Contents of this paper are solely the responsibility of the authors and do not necessarily represent the official view of the NIH.

\section{Author details}

'Department of Clinical Sciences, University of Texas Southwestern Medical Center, 5323 Harry Hines Blvd E1, 410D Dallas, TX, USA. ${ }^{2}$ Harold C. Simmons Comprehensive Cancer Center, Dallas, TX, USA. ${ }^{3}$ Department of Medicine, Division of Gastroenterology, Washington University School of Medicine, Saint Louis, MO, USA. ${ }^{4}$ Alvin J. Siteman Cancer Center at Barnes-Jewish Hospital, Washington University School of Medicine, Saint Louis, MO, USA. ${ }^{5}$ Department of Internal Medicine, Division of Gastroenterology, Moores Cancer Center, University of California, San Diego, CA, USA. ${ }^{6}$ Department of Veterans Affairs, San Diego Healthcare System, San Diego, CA, USA. ${ }^{7}$ Department of Surgery, Division of Public Health Sciences, Washington University School of Medicine, St Louis, MO, USA. ${ }^{8}$ College for Public Health and Social Justice, Saint Louis University, St. Louis, MO, USA.
Received: 26 September 2013 Accepted: 26 November 2014

Published: 9 December 2014

\section{References}

1. Mandel JS, Bond JH, Church TR, Snover DC, Bradley GM, Schuman LM, Ederer F: Reducing mortality from colorectal cancer by screening for fecal occult blood. Minnesota Colon Cancer Control Study. N Engl J Med 1993, 328:1365-1371.

2. Selby JV, Friedman GD, Quesenberry CP Jr, Weiss NS: A case-control study of screening sigmoidoscopy and mortality from colorectal cancer. N Engl J Med 1992, 326:653-657.

3. Jestin P, Nilsson J, Heurgren M, Pahlman L, Glimelius B, Gunnarsson U: Emergency surgery for colonic cancer in a defined population. Br J Surg 2005, 92:94-100.

4. Elliss-Brookes L, McPhail S, Ives A, Greenslade M, Shelton J, Hiom S, Richards M: Routes to diagnosis for cancer - determining the patient journey using multiple routine data sets. Br J Cancer 2012, 107:1220-1226.

5. Iversen LH, Bulow S, Christensen IJ, Laurberg S, Harling H, Danish Colorectal Cancer G: Postoperative medical complications are the main cause of early death after emergency surgery for colonic cancer. Br J Surg 2008, 95:1012-1019.

6. Diggs JC, Xu F, Diaz M, Cooper GS, Koroukian SM: Failure to screen: predictors and burden of emergency colorectal cancer resection. Am J Manag Care 2007, 13:157-164.

7. Paulson EC, Mahmoud NN, Wirtalla C, Armstrong K: Acuity and survival in colon cancer surgery. Dis Colon Rectum 2010, 53:385-392.

8. Pollock AM, Vickers N: Deprivation and emergency admissions for cancers of colorectum, lung, and breast in south east England: ecological study. BMJ 1998, 317:245-252.

9. Rabeneck L, Paszat LF, Li C: Risk factors for obstruction, perforation, or emergency admission at presentation in patients with colorectal cancer: a population-based study. Am J Gastroenterol 2006, 101:1098-1103.

10. Centers for Disease Control and Prevention: Cancer screening - United States, 2010. MMWR Morb Mortal Wkly Rep 2012, 61:41-45.

11. Shapiro JA, Klabunde CN, Thompson TD, Nadel MR, Seeff LC, White A: Patterns of colorectal cancer test use, including CT colonography, in the 2010 National Health Interview Survey. Cancer Epidemiol Biomarkers Prev 2010, 2012(21):895-904.

12. Lansdorp-Vogelaar I, Kuntz KM, Knudsen AB, van Ballegooijen M, Zauber AG, Jemal $A$ : Contribution of screening and survival differences to racial disparities in colorectal cancer rates. Cancer Epidemiol Biomarkers Prev 2012, 21:728-736.

13. DeSantis C, Naishadham D, Jemal A: Cancer statistics for African Americans, 2013. CA Cancer J Clin 2013, 63(3):151-166

14. Greenlee RT, Howe HL: County-level poverty and distant stage cancer in the United States. Cancer Causes Control 2009, 20:989-1000.

15. Cooper GS, Koroukian SM: Geographic variation among Medicare beneficiaries in the use of colorectal carcinoma screening procedures. Am J Gastroenterol 2004, 99:1544-1550.

16. Boulos DN, Ghali RR, Ibrahim EM, Boulos MN, AbdelMalik P: An eight-year snapshot of geospatial cancer research (2002-2009): clinicoepidemiological and methodological findings and trends. Med Oncol 2011, 28(4):1145-1162.

17. Schootman M, Lian M, Deshpande AD, McQueen A, Pruitt SL, Jeffe DB: Temporal trends in geographic disparities in small-area-level colorectal cancer incidence and mortality in the United States. Cancer Causes Control 2011, 22:1173-1181.

18. Lian M, Schootman M, Yun S: Geographic variation and effect of area-level poverty rate on colorectal cancer screening. BMC Public Health 2008, 8:358.

19. Lian M, Schootman M, Doubeni CA, Park Y, Major JM, Stone RA, Laiyemo $A O$, Hollenbeck AR, Graubard BI, Schatzkin A: Geographic variation in colorectal cancer survival and the role of small-area socioeconomic deprivation: a multilevel survival analysis of the NIH-AARP Diet and Health Study Cohort. Am J Epidemiol 2011, 174:828-838.

20. Mobley LR, Kuo TM, Urato M, Subramanian S: Community contextual predictors of endoscopic colorectal cancer screening in the USA: spatial multilevel regression analysis. Int I Health Geogr 2010, 9:44.

21. Sikka V, Ornato JP: Cancer diagnosis and outcomes in Michigan EDs vs other settings. Am J Emerg Med 2012, 30:283-292. 
22. Warren $J$, Klabunde CN, Schrag D, Bach PB, Riley GF: Overview of the SEER-Medicare data: content, research applications, and generalizability to the United States elderly population. Med Care 2002, 40:IV-3-18.

23. SEER Cancer Statistics Review, 1975-2007. In National Cancer Institute. Edited by Altekruse SF, Kosary CL, Krapcho M, Neyman N, Aminou R, Waldron W, Ruhl J, Howlader N, Tatalovich Z, Cho H, Mariotto A, Eisner MP, Lewis DR, Cronin K, Chen HS, Feuer EJ, Stinchcomb DG, Edwards BK. Bethesda, MD: National Cancer Institute; 2010. http://seer.cancer.gov/csr/1975_2007/, based on November 2009 SEER data submission, posted to the SEER web site.

24. Rabeneck L, Paszat LF, Rothwell DM, He J: Temporal trends in new diagnoses of colorectal cancer with obstruction, perforation, or emergency admission in Ontario: 1993-2001. Am J Gastroenterol 2005, 100:672-676.

25. Earle CC, Landrum MB, Souza JM, Neville BA, Weeks JC, Ayanian JZ: Aggressiveness of cancer care near the end of life: is it a quality-of-care issue? J Clin Oncol 2008, 26:3860-3866.

26. Schrag D, Cramer LD, Bach PB, Cohen AM, Warren JL, Begg CB: Influence of hospital procedure volume on outcomes following surgery for colon cancer. JAMA 2000, 284:3028-3035.

27. Krieger N, Chen JT, Waterman PD, Soobader MJ, Subramanian SV, Carson R: Geocoding and monitoring of US socioeconomic inequalities in mortality and cancer incidence: does the choice of area-based measure and geographic level matter?: the Public Health Disparities Geocoding Project. Am J Epidemiol 2002, 156:471-482.

28. Singh GK, Miller BA, Hankey BF, Edwards BK: Area socioeconomic variations in U.S. cancer incidence, mortality, stage, treatment, and survival, 1975-1999. In Book Area socioeconomic variations in U.S. cancer incidence, mortality, stage, treatment, and survival, 1975-1999. City: National Cancer Institute; 2003.

29. Poverty areas. [http://www.census.gov/population/socdemo/statbriefs/ povarea.html]

30. Krieger N, Chen JT, Waterman PD, Rehkopf DH, Subramanian SV: Race/ ethnicity, gender, and monitoring socioeconomic gradients in health: a comparison of area-based socioeconomic measures-the public health disparities geocoding project. Am J Public Health 2003, 93:1655-1671.

31. Charlson ME, Pompei $P$, Ales KL, Mackenzie CR: A new method of classifying prognostic comorbidity in longitudinal studies: development and validation. J Chronic Dis 1987, 40:373-383.

32. SEER-Medicare: Calculation of comorbidity weights. [http://healthservices. cancer.gov/seermedicare/program/comorbidity.html]

33. Parchman ML, Culler SD: Preventable hospitalizations in primary care shortage areas. An analysis of vulnerable Medicare beneficiaries. Arch Fam Med 1999, 8:487-491.

34. Schenck AP, Klabunde CN, Warren JL, Peacock S, Davis WW, Hawley ST, Pignone M, Ransohoff DF: Data sources for measuring colorectal endoscopy use among Medicare enrollees. Cancer Epidemiol Biomarkers Prev 2007, 16:2118-2127.

35. Measuring rurality: Rural-urban commuting area codes. [http://www.ers. usda.gov/data-products/rural-urban-commuting-area-codes.aspx]

36. Larsen K, Merlo J: Appropriate assessment of neighborhood effects on individual health: integrating random and fixed effects in multilevel logistic regression. Am J Epidemiol 2005, 161:81-88.

37. Larsen K, Petersen JH, Budtz-Jorgensen E, Endahl L: Interpreting parameters in the logistic regression model with random effects. Biometrics 2000, 56:909-914.

38. Merlo J, Chaix B, Ohlsson H, Beckman A, Johnell K, Hjerpe P, Rastam L, Larsen $\mathrm{K}$ : A brief conceptual tutorial of multilevel analysis in social epidemiology: using measures of clustering in multilevel logistic regression to investigate contextual phenomena. Journal of Epidemioloyg and Community Health 2006, 60:290-297.

39. Tiro JA, Kamineni A, Levin TR, Zhen Y, Schottinger JE, Rutter C, Corley D, Skinner CS, Chubak J, Doubeni C, Halm E, Gupta S, Wernli K, Klabunde CN: Conceptualizing the colorectal cancer (CRC) screening process in community settings: The population-based research optimizing screening through personalized regimens (PROSPR) network. Cancer Epidemiol Biomarkers Prev 2014, 23:1147-1158.

40. Weller D, Vedsted P, Rubin G, Walter FM, Emery J, Scott S, Campbell C, Andersen RS, Hamilton W, Olesen F, Rose P, Nafees S, van Rijswijk E, Hiom S, Muth C, Beyer M, Neal RD: The Aarhus statement: improving design and reporting of studies on early cancer diagnosis. Br J Cancer 2012, 106:1262-1267.
41. Walter F, Webster A, Scott S, Emery J: The Andersen Model of Total Patient Delay: a systematic review of its application in cancer diagnosis. $J$ Health Services Res Policy 2012, 17:110-118.

42. Olesen F, Hansen RP, Vedsted P: Delay in diagnosis: the experience in Denmark. Br J Cancer 2009, 101(Suppl 2):S5-S8.

43. Krieger N, Chen JT, Waterman PD, Soobader MJ, Subramanian SV, Carson R: Choosing area based socioeconomic measures to monitor social inequalities in low birth weight and childhood lead poisoning: The Public Health Disparities Geocoding Project (US). J Epidemiol Comm Health 2003, 57:186-199.

44. Krieger N, Waterman P, Chen JT, Soobader MJ, Subramanian SV, Carson R: Zip code caveat: bias due to spatiotemporal mismatches between zip codes and US census-defined geographic areas-the Public Health Disparities Geocoding Project. Am J Public Health 2002, 92:1100-1102.

45. Adler NE, Newman K: Socioeconomic disparities in health: pathways and policies. Health Aff 2002, 21:60-76.

46. Weinick RM, Zuvekas SH, Cohen JW: Racial and ethnic differences in access to and use of health care services, 1977 to 1996. Med Care Res Review 2000, 57(Suppl 1):36-54

47. Hayanga AJ, Waljee AK, Kaiser HE, Chang DC, Morris AM: Racial clustering and access to colorectal surgeons, gastroenterologists, and radiation oncologists by African Americans and Asian Americans in the United States: a county-level data analysis. Arch Surg 2009, 144:532-535.

48. Stimpson JP, Pagan JA, Chen LW: Reducing racial and ethnic disparities in colorectal cancer screening is likely to require more than access to care. Health Aff 2012, 31:2747-2754.

49. White A, Vernon SW, Franzini L, Du XL: Racial and ethnic disparities in colorectal cancer screening persisted despite expansion of Medicare's screening reimbursement. Cancer Epidemiol Biomarkers Prev 2011, 20:811-817.

50. O'Malley AS, Forrest CB, Feng S, Mandelblatt J: Disparities despite coverage: gaps in colorectal cancer screening among Medicare beneficiaries. Arch Intern Med 2005, 165:2129-2135.

51. Elferink MA, Pukkala E, Klaase JM, Siesling S: Spatial variation in stage distribution in colorectal cancer in the Netherlands. European journal of cancer (Oxford, England: 1990) 2012, 48(8):1119-1125.

52. Rushton G, Peleg I, Banerjee A, Smith G, West M: Analyzing geographic patterns of disease incidence: rates of late-stage colorectal cancer in lowa. J Med Syst 2004, 28:223-236.

53. Pruitt SL, Leonard T, Zhang S, Schootman M, Halm EA, Gupta S: Physicians, clinics, and neighborhoods: multiple levels of influence on colorectal cancer screening. Cancer Epidemiol Biomarkers Prev 2014, 23:1346-1355.

54. Smothers L, Hynan L, Fleming J, Turnage R, Simmang C, Anthony T: Emergency surgery for colon carcinoma. Dis Colon Rectum 2003, 46:24-30.

55. Ho YH, Siu SK, Buttner P, Stevenson A, Lumley J, Stitz R: The effect of obstruction and perforation on colorectal cancer disease-free survival. World J Surg 2010, 34:1091-1101.

56. Sjo OH, Larsen S, Lunde OC, Nesbakken A: Short term outcome after emergency and elective surgery for colon cancer. Colorectal Dis 2009, 11:733-739.

57. Hamilton W: Emergency admissions of cancer as a marker of diagnostic delay. Br J Cancer 2012, 107:1205-1206.

58. Winawer SJ, Fletcher RH, Miller L, Godlee F, Stolar MH, Mulrow CD, Woolf SH, Glick SN, Ganiats TG, Bond JH, Rosen L, Zapka JG, Olsen SJ, Giardiello FM, Sisk JE, Van Antwerp R, Brown-Davis C, Marciniak DA, Mayer RJ: Colorectal cancer screening: clinical guidelines and rationale. Gastroenterology 1997, 112:594-642.

59. Markowitz SD, Bertagnolli MM: Molecular origins of cancer: Molecular basis of colorectal cancer. N Engl J Med 2009, 361:2449-2460.

60. Schenck AP, Peacock SC, Klabunde CN, Lapin P, Coan JF, Brown ML: Trends in colorectal cancer test use in the medicare population, 1998-2005. Am J Prev Med 2009, 37:1-7.

\section{doi:10.1186/1471-2407-14-927}

Cite this article as: Pruitt et al:: Missed opportunities: racial and neighborhood socioeconomic disparities in emergency colorectal cancer diagnosis and surgery. BMC Cancer 2014 14:927. 